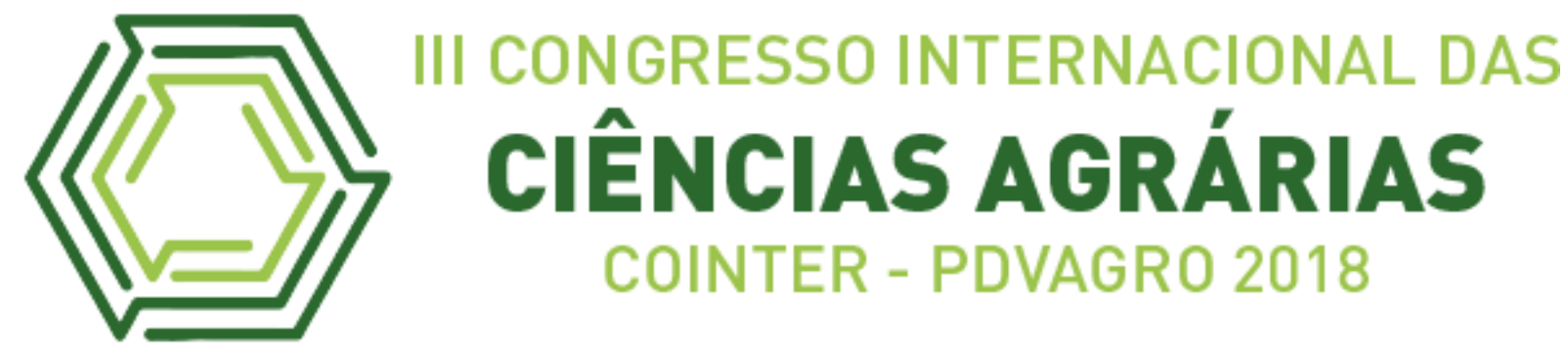

\title{
DESENVOLVIMENTO DE BISCOITOS ENRIQUECIDOS COM FARINHA DO RESÍDUO DE MURUCI (BYRSONIMA CRASSÍFOLIA (L): UMA ALTERNATIVA AO COMBATE AO DISPERDÍCIO
}

\section{DEVELOPMENT OF COOKIES ENRICHED WITH MURUCI (BYRSONIMA CRASSÍFOLIA (L)) RESIDUE FLOUR: AN ALTERNATIVE AGAINST WASTE.}

\author{
Apresentação: Pôster
}

Leandro José de Oliveira Mindelo ${ }^{1}$; Wanessa Ferreira dos Santos ${ }^{2}$; Jerson Pinto da Trindade ${ }^{3}$; Robson da Silveira Espíndola ${ }^{4}$ Evelyn Ivana Trindade Damasceno ${ }^{5}$

\section{DOI: https://doi.org/10.31692/2526-7701.IIICOINTERPDVAGRO.2018.00419}

\section{Introdução}

O muricizeiro (Byrsonimacrassífolia (L.) Kunth) pertence à família Malpighiaceae, nativa do Brasil e apresenta ampla distribuição geográfica no território brasileiro. Conhecido popularmente como murici, muruci, murixi, fruta de jacu, entre outros, dentre suas principais características estão o aroma e o sabor. O muruci é fruto carnoso, do tipo drupóide, com formato globoso ou oblongo, oriundo de ovário tricarpelado, cada carpelo contém um óvulo (BELISÁRIO e CONEGLIAN, 2013). Esse fruto consumido geralmente in natura apresenta sabor agridoce com leve adstringência devido à presença de taninos (MORZELLE et al., 2015). Além de apresentar-se como uma boa fonte de energia associado ao teor de lipídeos considerável, podendo ser utilizado no preparo de doces, licores, sucos e sorvetes, refrescos, geléias, pudins, pavês e outros (BRASIL, 2002). O murici apresenta teor de vitamina C apreciável, comparável aos teores encontrados nos brócolis, laranja pêra e no limão (PEREIRA e SANTOS, 2014). Além disso, este fruto tem apresentado um expressivo potencial antioxidante, com habilidade de sequestrar radicais livres (ROESLER et al., 2007). Todavia, do processamento industrial desta polpa, gera-se uma quantidade considerável de resíduos (borra e caroço) que frequentemente são descartados sem nenhum tratamento prévio podendo

\footnotetext{
${ }^{1}$ Engenharia de Alimentos, IFPA - Campus Castanhal, leandromindelo50@gmail.com

2Engenharia de Alimentos, IFPA - Campus Castanhal, wanessasal2@hotmail.com

${ }^{3}$ Engenharia de alimentos IFPA - Campus castanhal, jersonpinto36@gmail.com

${ }^{4}$ Engenharia de Alimentos, IFPA - Campus Castanhal, robsonespindola4@gmail.com

${ }^{5}$ Doutora, Instituto Federal de Educação, Ciência e Tecnologia do Pará, evelyn.damasceno@ifpa.edu.br
} 
acarretando sérios problemas ambientais. A crescente preocupação com possíveis impactos ambientais e o elevado índice de perdas e desperdícios gerados pelas indústrias de alimentos alertado a comunidade científica que buscam alternativas viáveis de aproveitamento e geração de novos produtos para o consumo humano (PEREIRA, 2005). O objetivo desta pesquisa consistiu em agregar valor aos resíduos gerados durante o processamento do muruci (Byrsonimacrassífolia (L.) Kunth) através do desenvolvimento de novos produtos (biscoitos) contribuindo para a redução dos impactos ambientais ocasionados pelo descarte dos resíduos na natureza.

\section{Fundamentação Teórica}

O murici é um fruto que tem gerado participação econômica crescente no agronegócio da região Norte, principalmente pela comercialização para consumo como fruta fresca e sob a forma de sucos, sorvetes, licores e geleias (ALVES \& FRANCO, 2003) que apresenta grande aceitação no mercado devido à sua cor atraente e ao seu sabor exótico.

O fruto do muruci (Byrsonima crassífolia (L.) Kunth)) apresenta sabor e aroma exótico, além das características de alto valor nutricional, representando uma importante oportunidade para pesquisas e investimentos tecnológicos para o processamento e reaproveitamento dos resíduos no desenvolvimento de produtos.

Monteiro e colaboradores (2015) observaram elevados teores de fibras na parte comestível da polpa de muruci, podendo contribuir com o enriquecimento da dieta regional em programas de suplementação alimentar como fonte deste nutriente.

A geração de resíduos está associada ao desperdício no uso de insumos, às perdas entre a produção e o consumo, e aos materiais que, gerados ao longo da cadeia agroindustrial, não possuem valor econômico evidente. Estima-se que, em média, de $20 \%$ a $30 \%$ da safra de grãos, de frutas e de hortaliças colhidas no Brasil sejam desperdiçados no caminho entre a lavoura e o consumidor. Os dados sobre o tipo e volume de resíduos gerados no agronegócio mundial sem valor agregado são escassos (ONG BANCO DE ALIMENTOS, 2004).

Resíduos podem representar perda de biomassa e de nutrientes, além de aumentar o potencial poluidor associado à disposição inadequada que, além da poluição de solos e de corpos hídricos quando da lixiviação de compostos, acarreta problemas de saúde pública. Por outro lado, o elevado custo associado ao tratamento, ao transporte e à disposição final dos resíduos gerados tem efeito direto sobre o preço do produto final. O aproveitamento de resíduos agroindustriais se mostra frente ao desperdício de alimentos, e ao beneficiamento e processamento desses, uma 
grande oportunidade de desenvolvimento de subprodutos, como também agregação de valor perdido, e utilização sustentável desses resíduos. Diversas agroindústrias têm realizado o aproveitamento de resíduos na produção de subprodutos, atentando a agregação de valor deste. Indústria de produção de queijos, utilizando o resíduo do soro lácteo na produção de bebidas fermentadas, onde também, os setores de produção animal, já utilizam o soro na incrementação de ração. Indústrias sucroalcooleiras utilizam o bagaço oriundo da produção de etanol, para fornecimento de energia nos fornos industriais das usinas. Os resíduos do beneficiamento de alimentos surgem durante o preparo destes, para a sua conversão em produtos alimentícios. Pertencem a este tipo, os resíduos que não se integram aos produtos como componentes e que por esse motivo necessitam serem deles excluídos. Este tipo de resíduo é eliminado dos alimentos durante o seu processamento e, por estratégias tecnológicas se tornam subprodutos.

\section{Metodologia}

\section{Amostragem}

Os frutos de muruci foram coletados em feiras livres de Castanhal-PA e transportados ao IFPA Castanhal. Em seguida foram higienizados em solução de hipoclorito de sódio a 150 ppm por 15 minutos e extraída a polpa manualmente. Dos resíduos obtidos, foram retiradas as sementes e aproveitada a "borra".

\section{Secagem da Torta}

O resíduo foi desidratado em estufa de circulação de ar a $60^{\circ} \mathrm{C}$ por aproximadamente 24 horas. Em seguida, o conteúdo seco foi triturado com o auxílio de liquidificador, e posteriormente embalado à vácuo e armazenado sob refrigeração.

Para o preparo da massa, inicialmente foram batidos os ovos, o açúcar e a gordura vegetal em batedeira Britânia, modelo turbo $360 \mathrm{~W}$ Prime, por 5 minutos até se obter um creme homogêneo. Ao creme, foram adicionados aos poucos, as farinhas e o fermento, até a homogeneidade da massa. Posteriormente os biscoitos foram moldados e padronizados e assados em forno elétrico à temperatura de $180^{\circ} \mathrm{C}$ por, aproximadamente 20 minutos. Após resfriados, os biscoitos foram armazenados em recipientes hermeticamente fechados.

\section{Análise sensorial e de intenção de compra}

Foi avaliada a aceitabilidade dos biscoitos por meio de escala hedônica estruturada de nove pontos. As amostras foram apresentadas a 32 provadores não-treinados e de forma aleatória, tendo como critério de exclusão, pessoas que apresentassem algum indicativo de situação que pudesse mascarar os resultados, tais como fumantes. Foram servidos em torno de 6-7 gramas 
de amostras em copos descartáveis de $50 \mathrm{~mL}$, codificados com números aleatórios, em temperatura ambiente. Todos os testes foram conduzidos no Laboratório de Análise Sensorial (IFPA- Castanhal). O índice de aceitabilidade foi calculado segundo a seguinte equação (Equação 01) abaixo: $\quad \mathrm{IA}(\%)=(\mathrm{A} \div \mathrm{B}) \times 100(1)$

Onde A (nota média obtida) e B (nota máxima obtida)

O teste de intenção de compra foi realizado através de ficha resposta com escala estruturada de 5 pontos, oscilando de 1 (certamente não compraria) a 5 (certamente compraria).

\section{Delineamento estatístico}

Os dados gerados pelos resultados da análise sensorial e de intenção de compra foram submetidos à análise estatística utilizando-se a análise de variância (ANOVA) em nível de significância a $5 \%$.

\section{Elaboração de biscoitos}

As formulações com diferentes porcentuais $(10,20,30 \%)$ de substituição da farinha de trigo foram denominadas $\mathrm{A}, \mathrm{B}, \mathrm{C}$.

Tabela 1. Formulações de biscoitos com substituição parcial da farinha de trigo

\begin{tabular}{|l|c|c|c|c|}
\hline \multicolumn{1}{|c|}{ Ingredientes } & Padrão & A (10\%) & B (20\%) & C (30\%) \\
\hline Farinha de trigo & $45 \%$ & $35 \%$ & $25 \%$ & $15 \%$ \\
\hline Amido de milho & $1,7 \%$ & $1,7 \%$ & $1,7 \%$ & $1,7 \%$ \\
\hline Fermento químico & $2,5 \%$ & $2,5 \%$ & $2,5 \%$ & $2,5 \%$ \\
\hline Açúcar mascavo & $11,4 \%$ & $11,4 \%$ & $11,4 \%$ & $11,4 \%$ \\
\hline Açúcar cristal & $16,6 \%$ & $16,6 \%$ & $16,6 \%$ & $16,6 \%$ \\
\hline Ovos & $11,4 \%$ & $11,4 \%$ & $11,4 \%$ & $11,4 \%$ \\
\hline Gordura vegetal 100\% & $11,4 \%$ & $11,4 \%$ & $11,4 \%$ & $11,4 \%$ \\
\hline Farinha do resíduo do muruci & $0 \%$ & $10 \%$ & $20 \%$ & $30 \%$ \\
\hline
\end{tabular}

\section{Resultados e Discussões}

Os índices de aceitabilidade das formulações (Tabela 1) não apresentaram diferença significativa entre as formulações ao nível de significância de 5\%. Ou seja, a substituição parcial usando farinha de resíduo de muruci não afetaram a aceitabilidade sensorial do produto quando comparado à formulação padrão ( $100 \%$ de farinha de trigo). Outro ponto interessante observado é que como não houve diferença significativa entre as formulações pode-se optar pelo uso da formulação mais aceita 
(C-30\%) visto que esta tende gerar um produto com maior perfil nutritivo em especial ao conteúdo de fibras. Silva et al (2011) ao desenvolver biscoitos a partir de resíduos de acerola encontraram índices de aceitabilidade que variaram de 5,31 a 6,17.

Abud e Narain (2009) demonstraram que biscoitos formulados com farinhas de resíduo do processamento de frutas podem vir a ser viáveis comercialmente, pois apresentaram boa aceitabilidade por grupos distintos.

Tabela 2: Índice de aceitabilidade (\%) das formulações F1, F2, F3 e F4 analisadas

\begin{tabular}{c|c}
\hline Formulação dos biscoitos & $\begin{array}{c}\text { Índice de } \\
\text { aceitabilidade } \\
(\%)\end{array}$ \\
\hline Padrão & 75,35 \\
\hline A (10\%) & 74,65 \\
\hline B (20\%) & 69,09 \\
\hline C (30\%) & 77,78 \\
\hline
\end{tabular}

Os dados de intenção de compra das formulações também não apresentaram diferença significativa ao nível de 5\% de significância entre as formulações. (Figura 1). No entanto apresentaram resultados positivos, especialmente para a formulação C (30\%) que apresentaram em torno de $65,63 \%$ de intenção de compra entre os provadores.

Figura 1: Intenção de compra (\%) das formulações com adição de 0\%, 10\%, 20\% e 30\% de farinha de resíduo de muruci.

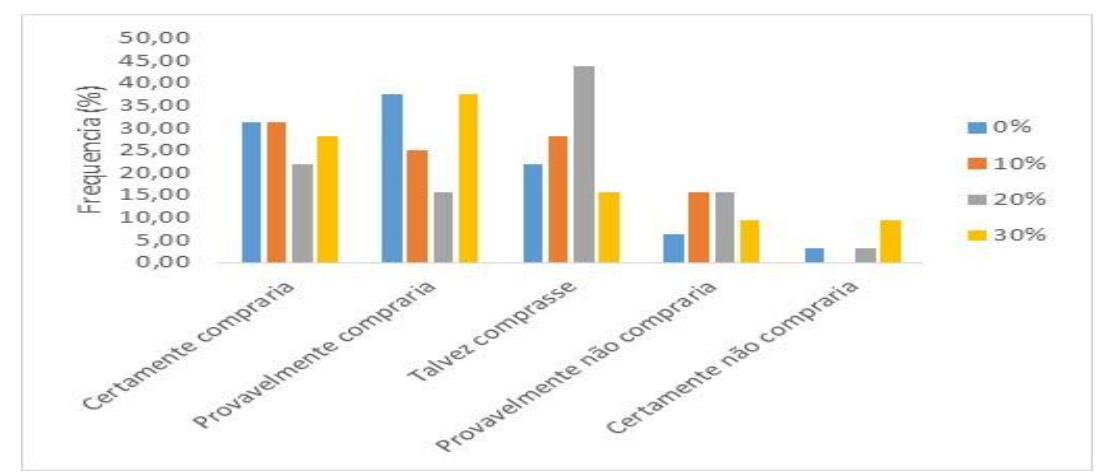

\section{Conclusões}

Os resultados mostraram que o aproveitamento dos resíduos do processamento de muruci pode ser uma alternativa eficiente e de baixo custo para o enriquecimento de produtos alimentícios, em função da elevada geração de resíduos sem valor comercial associada aos seus aspectos 
nutricionais, além de ser importante do ponto de vista ambiental e servir como fonte de suplemento na alimentação das classes sociais menos privilegiadas.

\section{Referências}

ABUD, A. K. S.; NARAIN, N. Incorporação da farinha de resíduo do processamento de polpa de fruta em biscoitos: uma alternativa de combate ao desperdício. Braz. J. FoodTechnol., v. 12, n. 4, p. 257-265, out./dez. 2009.

ALVES, G. L.; FRANCO, M. R. B. Headspace gas chromatography-mass spectrometry of volatile compounds in murici (Byrsonima crassifolia L. Rich). Journal of Chromatography, v. 985, n. 4, p. 297-301, 2003.

BELISÁRIO, C. M; CONEGLIAN, R. C. C. Qualidade de frutos de murici (Byrsonimacrassifolia, Malpighiaceae) armazenados sob refrigeração. Global Science and ENCICLOPÉDIA BIOSFERA, Centro Científico Conhecer - Goiânia, v.14 n.25; p. 2017240 Technology, v. 06, n. 2, p. 95-101, 2013.

COSTA FILHO, D. V; SILVA, A. J; SILVA, P. A. P; SOUSA, F. C. APROVEITAMENTO DE RESÍDUOS AGROINDUSTRIAIS NA ELABORAÇÃO DE SUBPRODUTOS. II Congresso Internacional de Ciências Agrarias. Comunicação Oral, 2017.

MONTEIRO, D.C.B; SOUSA, W.C; PIRES, C.R.F; AZEVEDO, L.A. BORGES, J.S. CARACTERIZAÇÃO FÍSICO-QUÍMICA DO FRUTO E DA GELEIA DE MURICI (Brysonima crassifólia). ENCICLOPÉDIA BIOSFERA, Centro Científico Conhecer Goiânia, v.11 n.21; p. 2015.

MORZELLE, M. C.; BACHIEGA, P.; SOUZA, E. C.; VILAS BOAS, E. V. B.; LAMOUNIER, M. L. Caracterização química e física de frutos de curriola, gabiroba e murici provenientes do cerrado brasileiro. Revista Brasileira de Fruticultura, v. 37, n. 1, p.96- 103, 2015.

ORGANIZAÇÃO NÃO GOVERNAMENTAL BANCO DE ALIMENTOS. Disponível em: http://www.bancodealimentos.org.br/porque/dados_fome.htm.

PEREIRA, A.C.; SANTOS, E. R. Frutas nativas do Tocantins com potencial de aproveitamento econômico. Revista Agri-Environmental Science, v. 1, n. 1, p. 22- 37, 2014

PEREIRA, C. A.; CARLI, L.; BEUX, S.; SANTOS, M. S.; BUSATO, S. B.; KOBELNIK, M.; BARANA, A. C. Utilização de farinha obtida a partir de rejeito de batata na elaboração de biscoitos. Universidade Federal de Ponta Grossa. Centro de Ciências Exatas Terra, Ponta Grossa, v.11, n.1, p.19-26, abril, 2005.

ROESLER, R.; MALTA, L. G.; CARRASCO, L. C.; HOLANDA, R. B.; SOUSA, C. A. S.; PASTORE, G. M. Atividade antioxidante de frutas do cerrado. Ciência e Tecnologia de Alimentos, v.1, n. 27, p. 53-60, 2007.

SILVA, I, F, B; SOUSA, B, A, A; BESERRA, A; SILVA, W.A; MEDEIROS, G.C.A. Anais do Encontro Nacional de Educação, Ciência e Tecnologia da UEPB. 2011.

SKLIUTAS, A. R.; Estudo do desenvolvimento de barra dietética de cereais e goiaba desidratada pelo processo de osmose a vácuo com utilização de fruto-oligossacarídeo. 2002. 116 p. Dissertação (Mestrado) - Universidade Estadual de Campinas, Campinas, 2002.

SOUZA， JNS; SILVA， EM; LOIR， A.; REES， JF; ROGEZ， H. LARANDELLE， Y. Capacidade antioxidante de quatro extratos de plantas amazônicas ricas em polifenóis: Um estudo de correlação usando ensaios químicos e biológicos in vitro. Food Chemistry, Reading, v.106, n.1, p. 331-339, 2008 